\title{
PACOPAMPA: UN COMPLEJO TEMPRANO DEL PERIODO FORMATIVO PERUANO
}

\author{
Hermilio Rosas La Noire y Ruth Shady Solis \\ Trabajo presentado al XXXIX Congreso Internacional de Americanistas, Lima, 1970
}

Nuestro interés por Pacopampa se inició a raíz de la visita efectuada por el Dr. Pablo Macera, director del Seminario de Historia Rural Andina de la Universidad de San Marcos, en 1966. A su regreso nos mostró fragmentos de cerámica colectados en superficie y nos refirió entusiasmado sus impresiones. En la muestra apreciamos diferencias estilísticas, que denotaban pertenecer a más de una época.

Revisando bibliografía, encontramos que las primeras menciones sobre el sitio, fueron dadas por Rafael Larco Hoyle en artículos periodísticos en Lima y Trujillo, el año 19391. El autor durante su corta permanencia había formado una valiosa colección de cerámica, objetos de piedra y hueso, parte de la cual dio a publicidad. A partir de esta fecha, se suceden errores tanto en la ubicación del sitio como en la procedencia e incluso función de los objetos. Rebeca Carrión Cachot, en 1948, ${ }^{2}$ ilustra equívocamente una figura de felino tallada en piedra, de tamaño casi natural, como mortero. (pag. 125, Fig. 12) y dos morteros también tallados como originarios del valle de Chicama (pag. 126, Figs. a, b). Igualmente en la obra póstuma Chavín, cultura matriz de la Civilización Andina de Julio C, Tello, Pacopampa es

1 La Crónica, Lima, 1o de Octubre de 1939, pp. 16-18, 26 u La Nación, Trujillo, 3 y 4 de octubre, 1939.

2 CARRIÓN CACHOT, Rebeca.- La Cultura Chavín, dos nuevas colonias: Kuntur Wasi y Ancón, Lima, 1948. ubicada en "las alturas del río Chancay..." (pag 24) u más adelante (pag 30) dentro de la provincia de Cutervo.

En base a estas evidencias, el Seminario de Historia Rural Andina, en colaboración con el Museo Nacional de Antropología y Arqueología, organizó un proyecto de investigación que empezó a funcionar en 1967.

\section{Pacopampa}

Pacopampa, nombre actual de un pueblo anexo al distrito de Querocoto, provincia de Chota, Cajamarca. Está ubicado en la vertiente oriental de la cordillera occidental andina, a los $79^{\circ} 1^{\prime}$ de longitud oeste y $6^{\circ} 20^{\prime}$ de latitud sur, entre el distrito de Huambos al Sur y poblaciones de la provincia de Cutervo al Norte y Este.

Los restos arqueológicos, distribuidos en un área extensa se concentran mayormente en el sitio ocupado por la población actual con su mayor exponente, una construcción piramidal erigida a un kilómetro al oeste del pueblo. Le corresponde una altura de 2410 msnm, zona del clima templado, con un promedio de 16 a $18^{\circ} \mathrm{C}$ de temperatura, especialmente dedicado a la agricultura de rakacha, maíz, frijol y calabaza. Esta zona es intermedia con la "jalca" fría y húmeda, rica en 
pastos de los 2800 a 3650 m y el "temple" cálido en la parte baja de las quebradas, apropiada para el cultivo de plantas como cacao, café, caña de azúcar, yuca, camote y cítricos.

La distancia que separa una zona de otra es corta, lo que permite una explotación ecológica variada. La topografía en general es accidentada, el otrora caudaloso río Chotano, afluente del Marañón, discurre en el fondo de la quebrada no pudiéndose, en consecuencia, aprovechar para la agricultura. Según la clasificación ecológica de Tosi ${ }^{3}$ esta zona corresponde al "bosque húmedo montano bajo".

\section{El TEMPLO, ALGUNAS CONSIDERACIONES GENERALES}

El templo con frente hacia el Este, ocupa una extensión aproximada de 600 por 300 m y una altura de $20 \mathrm{~m}$ sobre el nivel de la primera plataforma. Antes de iniciar nuestras excavaciones, aparentemente constaba de tres grandes plataformas superpuestas, posteriormente se constató que la primera y segunda se subdividían dando un total de cinco plataformas, separadas por grandes muros de piedra ${ }^{4}$ comunicadas por graderías frontales o tal vez galerías subterráneas ${ }^{5}$.

En un reconocimiento superficial, previo a nuestros trabajos, registramos diseminados en la superficie de las plataformas, fragmentos de columnas, cornisas talladas en relieve y restos de morteros de piedra. La mayor concentración se observó en la quinta plataforma, la más amplia. Estos restos sumados a los descubrimientos por nuestras excavaciones son:

- Columnas cilíndricas de $50 \mathrm{~cm}$ de diámetro, cuyo largo varía entre 1.50 y $2.10 \mathrm{~m}$ y poligonales de $75 \mathrm{~cm}$ de diámetro, largo desconocido.

- Cornisas talladas en alto relieve con figuras de serpientes, felinos, halcones y huella de pie humano.

3 TOSI, Joseph,. Zonas de vida natural en el Perú, pp. 162 171 .

4 Ver Muro A y Muro B.

5 Localizadas en la segunda, tercera y quinta plataforma.
- Felino tallado en tamaño casi natural.

- Galerías subterráneas de dimensiones variadas, exploramos dos en la cuarta plataforma, la Galería del Muerto hasta los $84 \mathrm{~m}$ y la Galería de la Serpiente hasta los $12 \mathrm{~m}$ ambas interrumpidas por derrumbes.

\section{EXCAVACIONES}

Teniendo en cuenta que el objetivo primordial de nuestro programa de investigaciones era realizar un reconocimiento general del contenido cultural del templo, más que excavaciones extensivas, nos limitamos a pequeños cortes estratigráficos exploratorios distribuidos en toda el área ocupada por la construcción, para de este modo conocer su filiación cultural y diferencias ocupaciones con significado temporal, si las hubiera.

Se hicieron un total de 16 cortes estratigráficos, ubicados en sitios que mostraban mayor acumulación de restos, especialmente cerámica, en superficie. Presentaron estratificación 8 cortes, no así 3, muy superficiales y disturbados por el cultivo y otros 5 sin materiales culturales.

\section{Se distinguieron 5 estratos (Fig.2)}

La capa 1, corresponde a la ocupación de las ruinas, es de color marrón oscuro, humosa, muy disturbada por el arado. Es frecuente encontrar elementos culturales Cajamarca, en asociación a cerámica de estilo Chavín; probablemente como resultado de una corta permanencia que no dejó mayor acumulación y la intensa actividad agrícola. No cubre toda el área de las ruinas, aparece únicamente en 2 cortes y rellenos de las graderías en la segunda y tercera plataforma.

Capa 2, constituida por tierra negra compacta, humosa, similar a la anterior, especialmente en las áreas donde no hubo ocupación Cajamarca. Los restos culturales son de estilo Chavín. Esta cultura tiene una distribución amplia, se encuentra en la mayoría de cortes, salvo en $8,11,10,12,15$ ubicados todos en el mismo sector. Tiene un espesor de 15 a $20 \mathrm{~cm}$ y en el corte de $1 \mathrm{~b}$, alcanza de 0.80 a $1.10 \mathrm{~m}$ tal vez por tratarse de material relleno. 


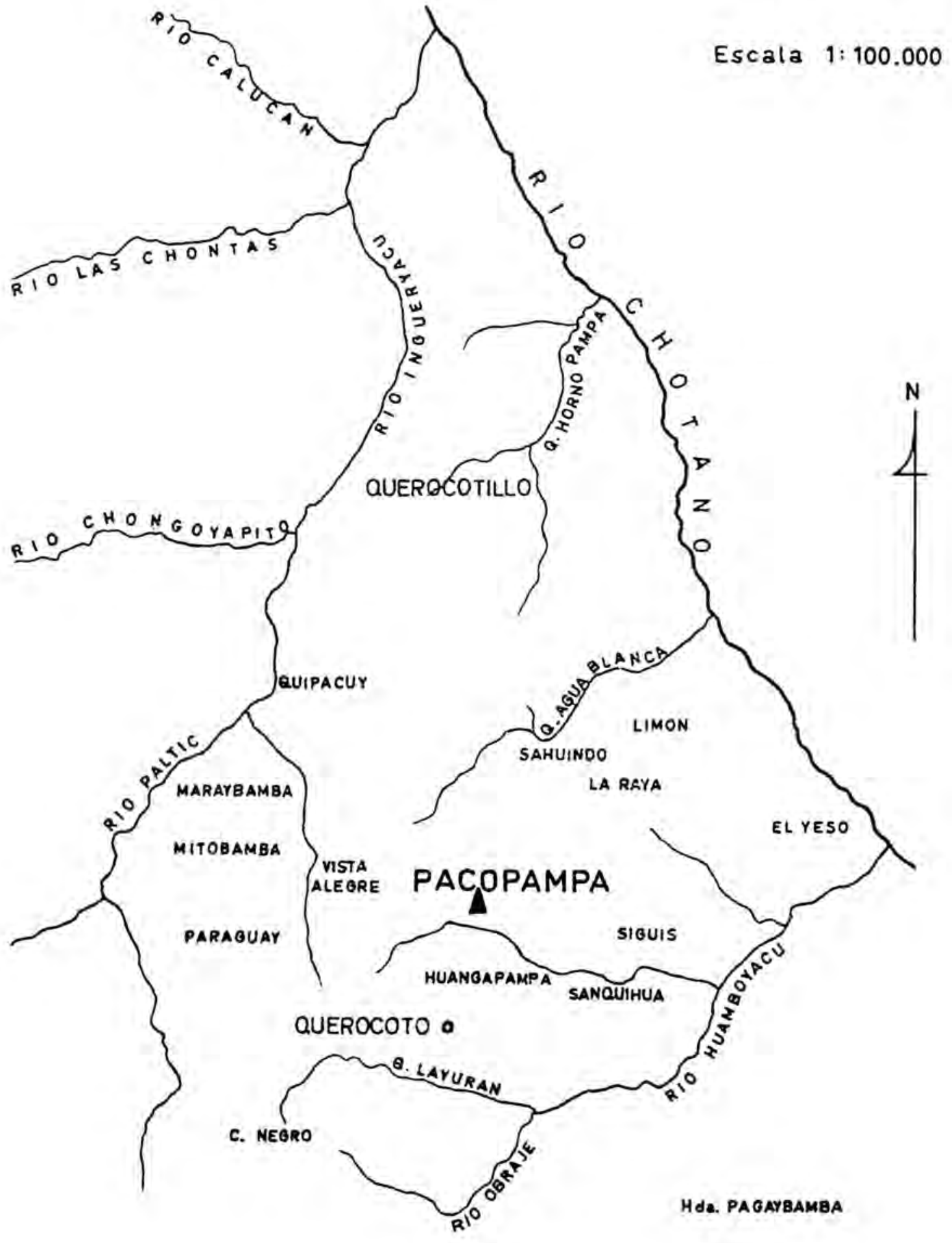

Figura 1. Parte de la Cuenca de Río Chotano y la ubicación del Centro Formativo de Pacopampa. 


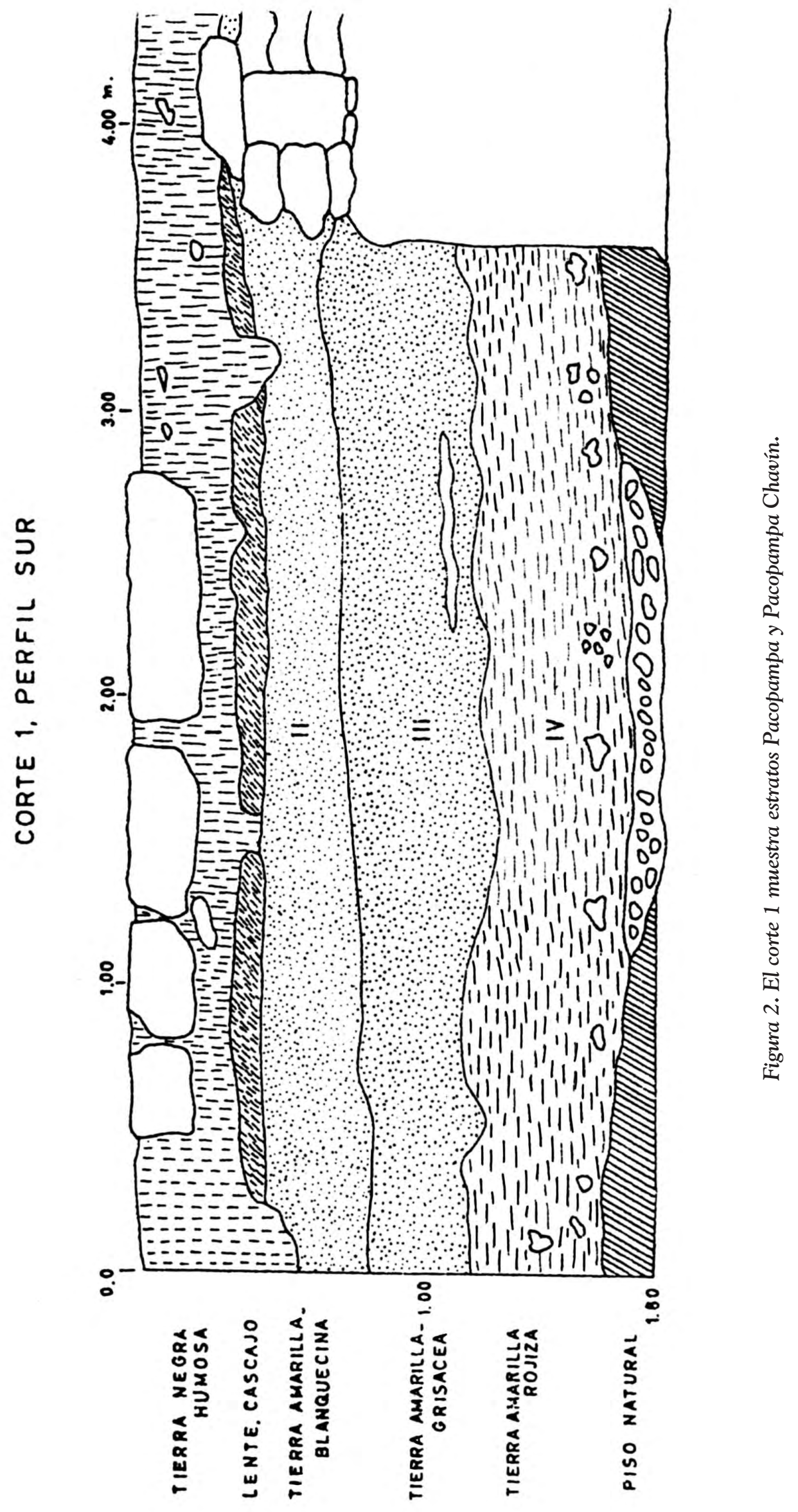


Capa 3, este estrato en los cortes 1 y lb está separado del anterior por una capa de tierra con abundante cascajo; sin material cultural, de $8 \mathrm{~cm}$ en el corte 1 y $80 \mathrm{~cm}$ en el corte lb. En este, probablemente como relleno para la construcción de una galería.

Es de color amarillo blanquecino, compacta, difícil de trabajar. Contenido cultural escaso, diferente del material Chavín, que estamos llamando Pacopampa.

En el sector sin ocupación Chavín, este estrato es el primero.

Capa 4, tierra arcillosa amarilla grisácea, oscura en el corte 5, por la abundancia de carbón y ceniza. Le caracteriza el aumento considerable de cerámica y un alto porcentaje de pintados pre y post cocción. Material Pacopampa, de 40 a $60 \mathrm{~cm}$ de espesor.

Capa 5, de consistencia suave, de color amarillo rojizo con adición de piedra y cascajo. Disminución de elementos culturales. Corresponde a la primera ocupación de las ruinas, asentada sobre pequeños montículos naturales. Tiene un espesor promedio de $70 \mathrm{~cm}$ y está presente en todos los cortes efectuados, salvo los estériles.

Los ochos cortes con estratificación han puesto de manifiesto una larga ocupación diferenciada en el tiempo. Los tres estratos más antiguos corresponden a establecimientos humanos pre-chavín, que estamos denominando Pacopampa con un promedio de $1.70 \mathrm{~m}$ de espesor. Se superpone a estos un estrato de 50 a $70 \mathrm{~cm}$ con material cultural Chavín y la última ocupación, sólo por $20 \mathrm{~cm}$, pertenece a la cultura Cajamarca. Igualmente importante es notar que toda la extensión explorada revela presencia de la cultura Pacopampa; menos amplia es la distribución Chavín; el periodo Cajamarca, está ausente en muchas áreas.

Las estructuras puestas a descubierto por las excavaciones o limpieza de algunos sectores son:

Muro A, entre la tercera y cuarta plataforma, descubierto en el corte lb, evidencia en sus 5 metros de altura, diferente técnica de cons- trucción, que probablemente corresponde a épocas también distintas. Las hiladas inferiores son de mampostería ordinaria de grandes piedras cortadas en forma irregular e intercaladas con otras más pequeñas como cuña. Aproximadamente de los 3.50 a $1.10 \mathrm{~m}$ las piedras son canteadas y su tamaño ha disminuido. En las hiladas superiores son finamente talladas, muy regulares, cortadas a escuadra. Los $4.40 \mathrm{~m}$ inferiores de la pared estuvieron asociados con material pre-chavín o Pacopampa; en cambio, la continuación hasta la superficie con elementos integrante Chavín (Fig. 3).

Muro B, divisorio entre la cuarta y última plataforma, tiene una longitud de $118 \mathrm{~m}$ y 3.50 $\mathrm{m}$ de altura, actual. Al igual que el anterior ofrece diferencias en los materiales y estilo. Pero esta vez a lo largo de la construcción, En los primeros $28 \mathrm{~m}$ de norte a sur, las piedras toscas y grandes están dispuestas en posición alternada horizontal-vertical, los $48 \mathrm{~m}$ siguientes tienen piedras seleccionadas de bordes regulares colocadas en orden horizontal, teniendo como cuñas laminas delgadas y pequeñas "pachillas". El tramo final está construido con piedras pequeñas y grandes, toscas y labradas sin el orden de los anteriores.

Muro C, separa la primera y segunda plataforma, descubierto en el corte 5. Por el estilo y técnica se relaciona con las hiladas superiores del muro A.

\section{LA PLAZA SAGRADA Y \\ EL TEMPLO DE LAS COLUMNAS}

Descubiertos en la quinta plataforma. La plaza de plano cuadrado cubre un área de $30 \times 30$ m, construida a $1.18 \mathrm{~m}$ debajo del nivel de piso, circundada por muros de una sola cara; las piedras, finamente talladas, están dispuestas en orden vertical-horizontal, patrón semejante al descrito en el primer sector del Muro B. Está comunicada por un sistema de graderías ubicadas en lados opuestos, de entrada por el Oeste y de acceso al templo de las columnas por el Este; tiene por piso, baldosas de piedra pizarra de forma irregular pero superficie plana conectado a una red de canales de desagüe. De la limpieza de los muros circundantes proviene 


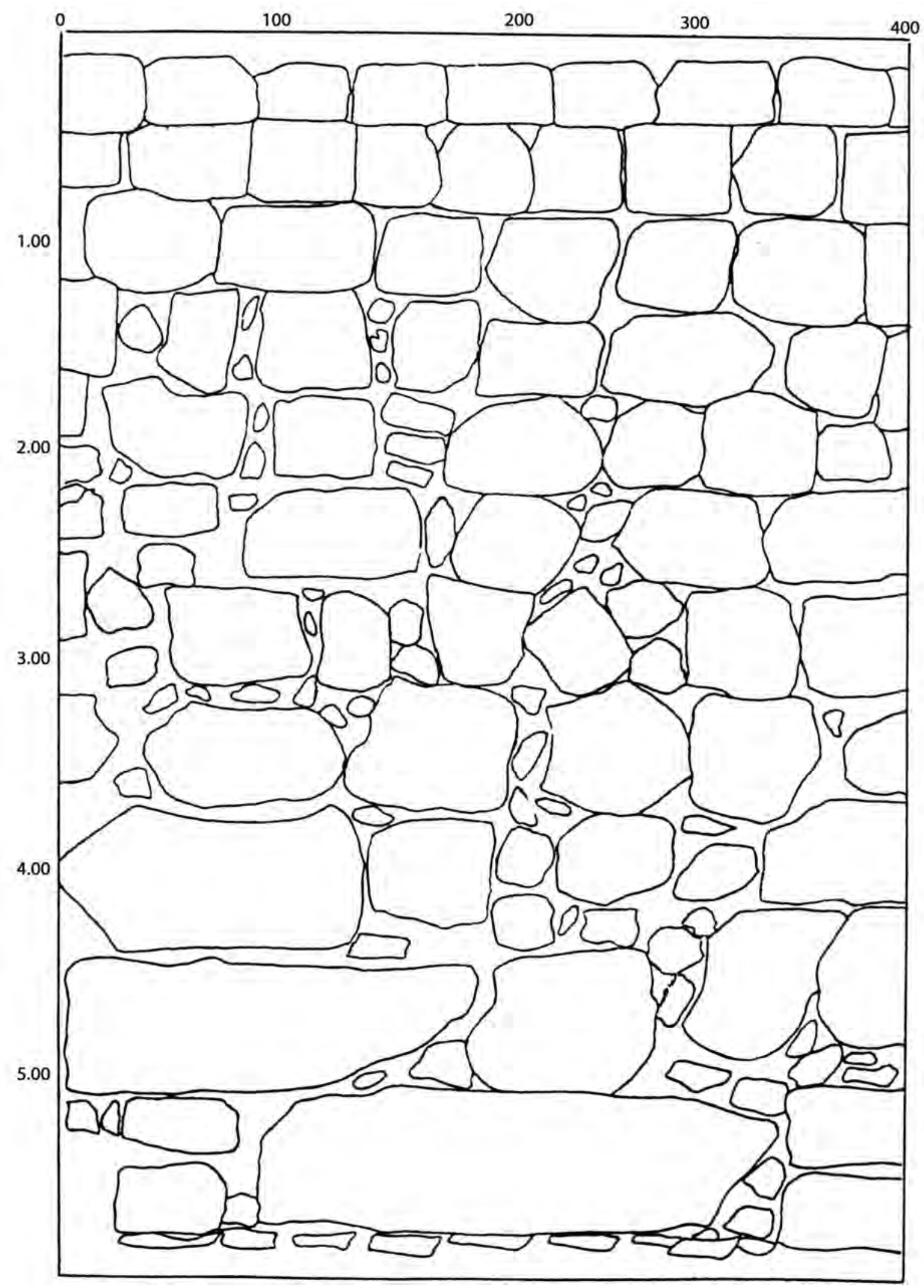

Figura 3. Muro A. 
abundante cerámica Chavín asociada a huesos de auquénidos y venados, muchos finamente tallados ${ }^{6}$.

En la limpieza de la grada Este, encontramos en sus extremos columnas caídas que al levantarlas in situ parecían formar parte de una portada, similar a Chavín de Huántar. Esta grada comunicaba con un recinto circular (no excavado todavía), en cuyo lado opuesto estaban esparcidas algunas columnas poligonales.

En el relleno de la grada ubicamos un probable entierro intrusivo con cerámica Cajamarca.

Sumarizando, se distinguen las siguientes técnicas de construcción:

- Mampostería tosca, constituida por grandes piedras que se intercalan con otras pequeñas. La irregularidad en las uniones fue cubierta con barro arcilloso. Presente en las hiladas inferiores del Muro A, asociada con cerámica Pacopampa.

- Construcciones de piedra uniformemente talladas, dispuestas en alternancia verticalhorizontal. Corresponde a la plaza sagrada y primeros $28 \mathrm{~m}$ del Muro B. Se asemeja en estilo a la fachada norte del templo de Sechín en Casma ${ }^{7}$, salvo las representaciones de figuras y a Tiahuanaco.

- Construcciones de grandes piedras rectangulares cuidadosamente talladas, unidas con pachillas. Segundo sector del muro B, las últimas hiladas del Muro A, y probablemente el Muro C; quizá similar al muro exterior del templo del Lanzón ${ }^{8}$.

- Arquitectura tosca, en base a piedras de forma y tamaño variados, mayormente erosionados, colocadas sin orden. Tramo final del Muro B y tal vez algunas edificaciones cuyos cimientos son visibles en sectores de la superficie de la última plataforma.

6 El Sr. T. Ueno ha identificado huesos de Camelidae y Odocoileus peruvianus. De esta zona proceden las mejores piezas cerámicas y tallas de hueso, especialmente numeroso es el tipo modelado cintado.

7 TELLO, Julio C. Arqueología del Valle de Casma, Lima, 1956, pp. 110.

8 LUMBRERAS, Luis y AMAT, Hernán. Informe preliminar sobre las Galerías Interiores de Chavín, Lima, 1959, pp. 149.

\section{ENTIERROS Y SU SIGNIFICADO TEMPORAL}

En la limpieza del Muro B, hallamos casi adosados a él, 6 entierros, de los cuales solo 2 presentaban ofrendas $(3$ y 6$)$ y también únicamente 2 estaban intactos (5 y 6 ), pudiéndose reconstruir su posición horizontal.

Fueron depositados en el suelo natural, empleando lajas de piedra delgadas "laimoscas", para cubrir las foses en forma transversal. Los entierros con ofrendas que correspondían a personas adultas, llevaban pintura roja en algunos huesos. En el número 6, el más intacto, el cadáver estaba en posición sentada con las piernas flexionadas hacia el pecho y la cara con la dirección al Este; sobre la cabeza tenía un plato de arcilla gris pulido con decoración bruñida, en la boca llevaba un trozo de colorante dentro del cual había un pedazo de cristal de roca; parte del colorante disuelto con la humedad impregnó los huesos largos de la pierna. El entierro número 3, muy disturbado, tenía por ofrenda un plato gris pulido con círculos estampados, depositado cerca al cráneo. No se pudo identificar la posición ni orientación.

El entierro número 5 correspondía a un párvulo, en posición extendida cúbito dorsal, orientado hacia el nor-este. Estaba cubierto por tres lajas.

Los entierros corresponden a la fase Pacopampa-Chavín, filiación cultural sugerida por las ofrendas.

\section{IDENTIFICACIÓN CULTURAL}

El análisis de la cerámica proveniente de los cortes excavados y su correlación estratigráfica, demostraron acentuadas diferencias que nos introdujeron al establecimiento de tres fases culturales, denominados Pacopampa, Chavín y Cajamarca, a los que corresponde determinada técnica y estilo arquitectónico, cerámica, lítico, óseo, etc.; si bien es cierto que dentro de cada una se observan cambios, probablemente con significado temporal, estos sólo podrán se concretados al terminar el estudio del material. 


\section{Cerámica Pacopampa}

Corresponde a la primera ocupación cerámica del lugar; en los cortes estratigráficos de mayor profundidad, alcanza $1.70 \mathrm{~m}$ de acumulación, debajo del estrato Chavín. El espesor, sumado a los cambios físicos que se observa (tres estratos bien diferenciados) y la cerámica, parece involucrar más de un periodo de desarrollo.

\section{Pasta}

Manufactura, probablemente enrollada, sin mostrar huellas de unión, temperante calcáreo, menudo pero de distribución uniforme, pasta deleznable, color marrón o rojo. Cocción defectuosa, reducida u oxidada.

\section{Tratamiento}

El acabado de la superficie es variado, alisado tosco, pulido opaco a un buen pulido en el interior, es común el empleo de engobe rojo.

\section{Forma}

Las formas típicas de las vasijas incluyen:

- Bols de borde directo, curvado hacia adentro, labio redondeado, base cóncava.

- Bols de borde expandido, labio redondeado, adelgazado, dentado, lobulado, almenado, aquillado, base redonda o aplanada.

- Bols de lados expandidos hacia la boca, con leve engrosamiento en esta sección, labios redondos y adelgazados o de borde fuertemente engrosado a menudo en el exterior, base semiplana. Menos frecuente es un bol de paredes verticales, labio plano, redondo y engrosado.

- Jarras de cuerpo globular, cuello cóncavo, ligeramente constreñido, borde evertido que puede engrosarse hacia la boca, labio redondo.

- Jarras de cuerpo esférico, cuello vertical o casi inclinado hacia el interior, labio redondeado.

- Jarras de cuerpo redondo, cuello corto evertido que se une al cuerpo formando ángulo agudo en el interior, labio redondo.

- Jarras de cuello corto, borde reforzado, doblado exteriormente, cuerpo globular.

- Jarras sin cuello, borde directo, inclinado hacia el interior labio redondo.

- Fragmentos de gollete escribo, labio adelgazado o redondo. Una vasija completa, proveniente de una colección particular tiene un gollete tubular, labio simple unido a un asa arqueada también tubular que se asienta sobre la superficie convexa del cuerpo. Este, probablemente se formó juntura agudamente marcada.

La frecuencia de cerámica decorada es alta, limitada a la superficie externa, rara vez en la base o el exterior. Técnica y diseños variados. Los principales tipos son:

Pacopampa inciso cortante, incisiones cortantes anchas y profundas (11-32 $\mathrm{mm}$ de ancho y $9-20 \mathrm{~cm}$ de profundidad), trazo irregular cama áspera, sobre superficie externa pulida opaco. Los diseños más frecuentes son geométricos, bandas horizontales, emes entrelazadas, cuadrados, rectángulos, círculos simples o en relieve, escalones simples o dobles; también se encuentran representaciones figurativas, caras de perfil o de frente, algunas con rasgos felínicos aparecen desde la parte media de la fase y algunos sombreados o hatching (Fig. 4).

Pacopampa inciso policromo, incisiones delgadas, efectuadas sobre arcilla en proceso de secado, cama irregular, separan áreas pintadas de color rojo, rojo indio, blanco o plomo. Los colores siempre alternados. El labio generalmente está pintado de rojo, la superficie interna lleva engobe rojo o blanco, muy pulido. Diseños geométricos, bandas horizontales, rectángulos, etc. (Fig. 5 y 11).

Pacopampa inciso superficial, incisiones finas superficiales (5-7 mm de ancho), sobre superficie externa bien pulida.- Diseños similares al tipo inciso cortante pero frecuentemente asociados con apéndices modelados.

Pacopampa pintado post-cocción, se diferencia del tipo inciso cortante por la aplicación de pintura roja, post-cocción sobre la superficie externa. Es difícil determinar si era total o úni- 


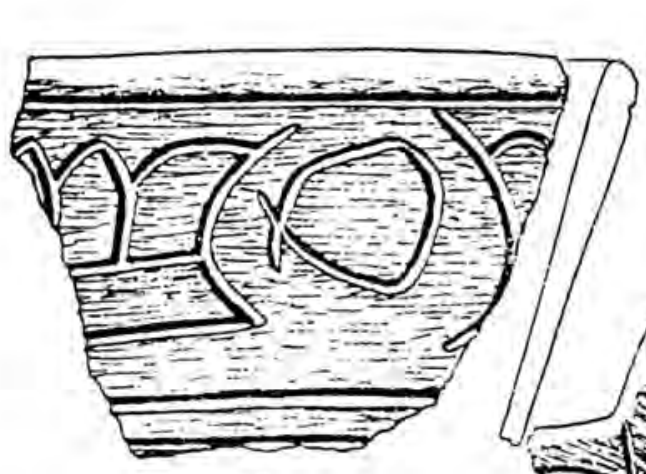

a

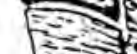

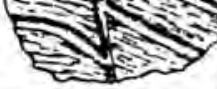
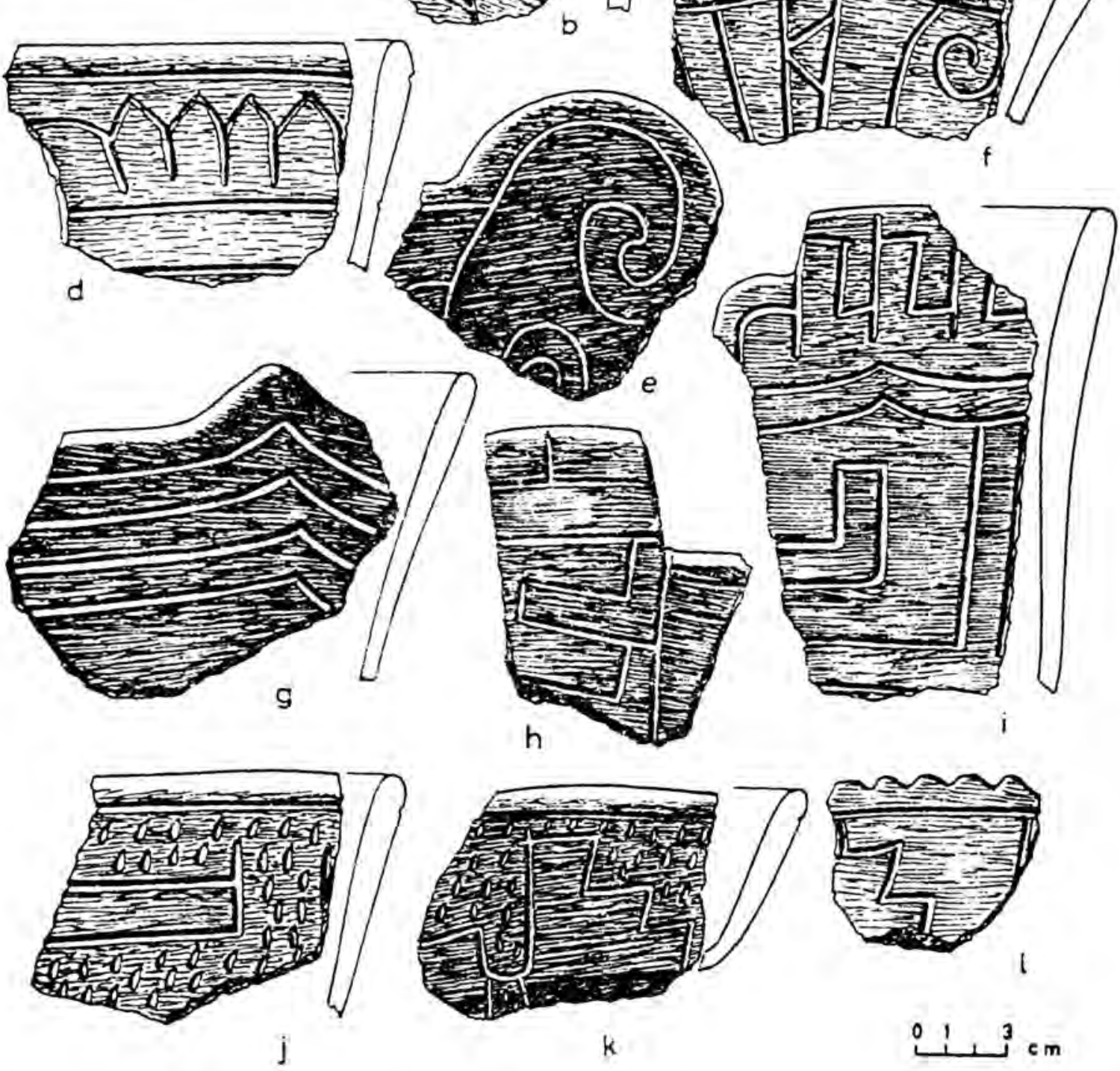

Figura 4. Fase Pacopampa, tipo Inciso Cortante. 

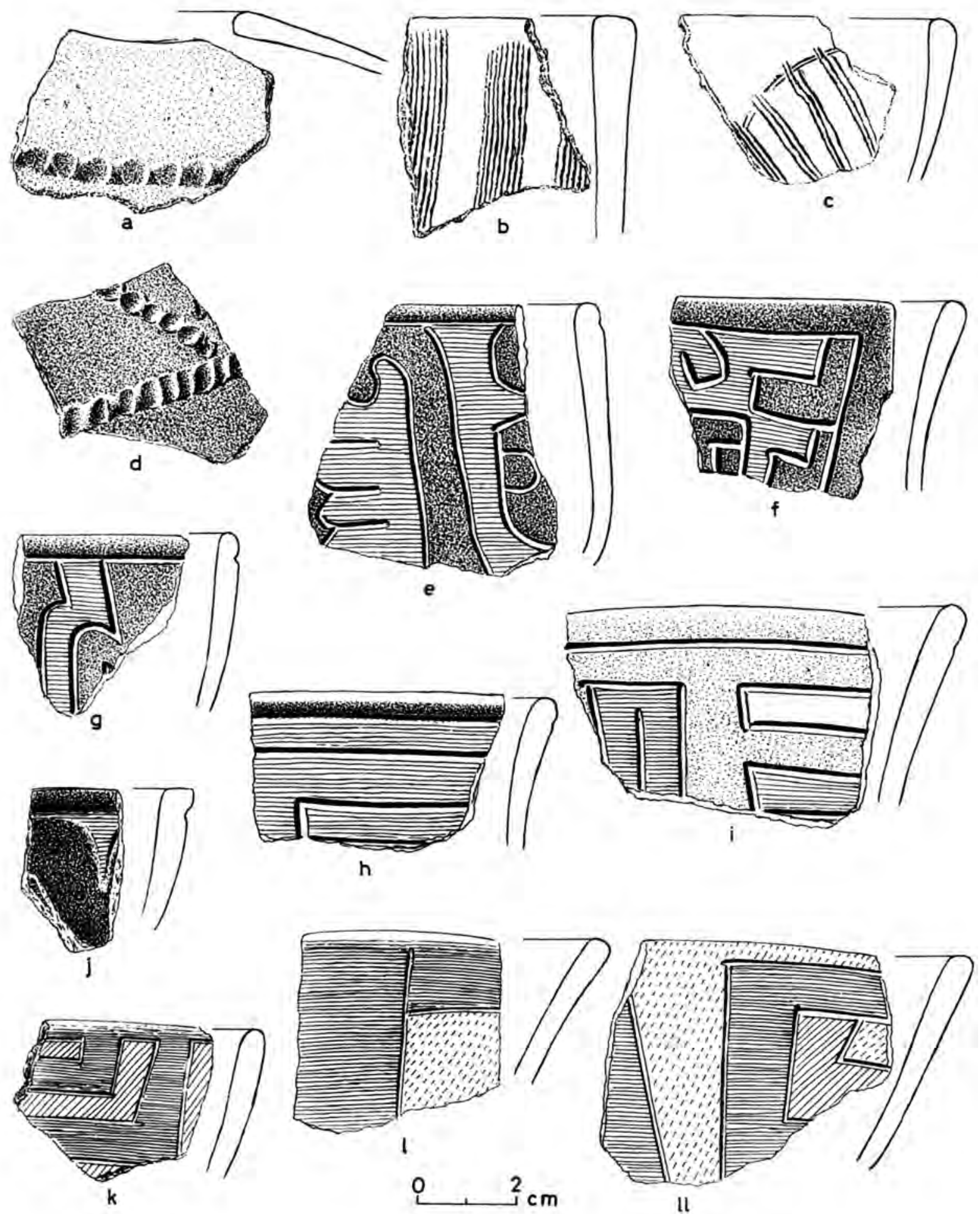

Figura 5. Fase Pacopampa, a, d: tiras sobrepuestas; b, c: Peinado; c, h: postcocción; i, k-ll: pintado policromo. 
camente en áreas debido al deterioro causado por la humedad (Fig. 5 e-g).

\section{Pacopampa tiRAS SOBRepuestas}

Delgadas cintas de arcilla aplicadas sobre el cuerpo externo de las vasijas, mayormente cerradas, luego presionadas con el dedo o con un instrumento. La superficie es alisada o pobremente pulida salvo la sección superior del borde, engobada de rojo. Un tiesto se encuentra asociado con protuberancias circulares punteadas en el centro. (Fig. 5, e, d).

Otros, escasos tiestos incluyen las siguientes técnicas decorativas: exciso rellenado con pintura roja post-cocción (Fig. 5, j) punteado oval en zonas, delimitadas por incisiones cortantes; peinados (Fig. 5, b, c). Rara es la presencia de un bol con reborde o "pestaña", inciso, aplicado a pocos centímetros debajo del labio, además se encuentra 2 tiestos que presentan brazos modelados, uno con los dedos de la mano doblados hacia arriba, 2 muestran pies; otros la cara de un ave con ojos circulares y el pico saliente, ala de ave, caras felínicas con colmillos y la nariz enrollada hacia arriba, etc.

En piedra, únicamente una cuchara pequeña que tiene en el mango la cara triangular, representada en el tipo inciso cortante.

\section{Fase Pacopampa-Chavín}

El estrato de esta fase se diferencia marcadamente del interior en textura, color y contenido cultural. En dos de nuestros cortes (1 y 1b) se encuentra una capa delgada intermedia estéril.

La cerámica Pacopampa-Chavín está asociada con nuevas técnicas de fabricación, modelado; mejor acabado; nuevas formas y decoración. Desaparecen los tipos incisos cortante, inciso policromo, inciso superficial, tiras superpuestas y son reemplazados por otros; no obstante hay formas y diseños tradicionales, que continúan en nuevas combinaciones y mayor variedad de presentación; tales como los bols de labios almenados, lobulados, aquillados, re- presentaciones felínicas, diseños escalonados, pintura roja post-cocción, etc.

Al igual que en la fase Pacopampa, se puede subdividir en unidades más cortas con significado temporal.

\section{Pasta}

La cerámica es de manufactura acordelada o modelada, pasta fina, compacta, antiplástico rocoso con intrusiones de mica, abundante, irregularmente distribuido. La cocción sigue mostrando deficiencia pero ha mejorado notablemente.

\section{Tratamiento}

Superficie muy bien pulida en especial el exterior. Aplicación de engobe rojo en algunos tipos.

\section{Forma}

Bols de borde directo, labio redondo o rebajado en el exterior, contorno almenado, lobulado, aquillado, angular o con vertedera en el labio, base aplanada.

- Bols de borde inclinado externo, labio redondeado o plano, contorno similar al anterior.

- Bols de borde inclinado hacia el interior, labio redondo, rebajado exteriormente, base convexa o aplanada.

- Bols de borde acampanado, fuertemente evertido en el extremo superior donde fue decorado internamente, labio plano, base convexa.

- Bols de lados verticales cortos, predomina el diámetro a la altura, labio redondo, silueta irregular debido a la ejecución de figuras modeladas en el exterior, base plana.

- Jarras de cuerpo probablemente globular, cuello ancho de paredes verticales, labio plano. 
- Jarras de cuerpo globular, gollete grueso, tronco cónico, borde engrosado exteriormente, labio plano.

- Jarras de asa estribo que presenta variaciones en el grosor y forma del gollete, delgado o grueso, con una cinta de arcilla aplicada en el exterior de la boca, labio pronunciado, plano o redondo.

- Jarras sin cuello, borde inclinado hacia el interior, algunos engrosados hacia la boca, labio redondo.

Los motivos decorativos son variados, realizados con técnica elaborada, frecuentemente sobre la superficie externa; en menor proporción en el interior de las vasijas y rara vez en la base.

Los tipos llanos identificados son, Pacopampa alisado y Pacopampa Rojo Llano; y entre los decorados:

\section{Pacopampa acordonado}

Aplicación de cordones de arcilla sobre el área media superior externa de grandes jarras sin cuello. Los cordones generalmente llevan incisiones anchas y profundas, separando en algunos casos, zonas punteadas; otros tienen doble cordón que se enlazan a intervalos (Fig. $6 a-b, d-e)$.

\section{Pacopampa Línea brunida}

Sobre la superficie alisada o pulida, se han ejecutado líneas bruñidas, en dos variedades: 1) en el interior de bols, color gris o rojo, líneas diagonales paralelas, formando triángulos convergen a una ancha banda bruñida que bordea la boca y el fondo de la vasija; 2) las jarras color rojo llevan las líneas bruñidas en el exterior pulido opaco, paralelas o cruzadas (Fig 7, d, f, h-i)

\section{Pacopampa Modelado cintado}

Se caracteriza por ser figurativo, para resaltar los rasgos físicos (boca, colmillos, ojos, nariz), se agregó cintas de arcilla, previamente elabo- radas en contraste de alto y bajo relieve, también se observa incisiones anchas y excisiones complementarias. Los canales se separación entre relieve pueden llevar pinturas rojas postcocción. Corresponde a grandes jarras, o urnas efigie (Fig. 8, a-b) .

\section{Pacopampa Gris pulido}

El más popular y característico del periodo. Incisiones de trazo regular bien ejecutadas, cama pulida con $26 \mathrm{~mm}$ de ancho por $14 \mathrm{~cm}$ de profundidad, sobre superficie externa gris, muy bien pulida. Los motivos frecuentes son círculos estampados, simples o dobles, con o sin punto con múltiples combinaciones, algunas veces asociados a decoración bruñida en el interior y escasa en el exterior. En este grupo persisten formas de la fase anterior, bols con bordes almenados, lóbulos, aquillados, etc.; también son frecuentes las vasijas de asa estribo (Fig. 8, c-f).

\section{Pacopampa Negro Inciso}

Incisiones anchas, trazo uniforme, cama limpia, pulida. Los diseños son ejecutados en la superficie interna, pocos en el exterior; es frecuente el uso de pintura roja post-cocción en las incisiones. Las figuras más comunes son serpientes, felinos o bandas. Predominan los bols de forma acampanada y las jarras de gollete estribo; superficie altamente pulida (Fig. $7, \mathrm{~b}, \mathrm{e}, \mathrm{g})$.

\section{Pacopampa Rojo grafitado}

La decoración puede ir sobre la superficie externa o interna de bols o jarras, engobadas de rojo; los diseños mayormente geométricos están hechos a base de incisiones anchas (21 $30 \mathrm{~mm}$ ), trazo regular, cama pulida, cubierta con grafito.

\section{Pacopampa Tojo inciso fino}

En los bols con engobe total rojo, se trazaron líneas delgadas y superficiales cuando la arcilla 
estaba próxima a secarse, en consecuencia, las incisiones tienen los márgenes estriados. Los diseños se limitan a la superficie externa, debajo del labio; el interior tiene pulido brillante, raras veces con líneas bruñidas. Forman bandas o triángulos con líneas sombreadas en su interior (Fig. 6, c, f-i).

Otros. - También corresponde a esta fase, artefactos de hueso, pendiente con imagen de felino tallada, espátulas de formas y tamaño variado, llanas o grabadas, punzones, agujas; artefactos de piedra, morteros, simples o tallados, estatuilla; y un fragmento de aguja de cobre.

\section{Comparaciones CUlturales}

En Pacopampa nos hallamos frente a una nueva cultura, desarrollada en un medio ecológico particular, que presenta algunos elementos culturales comunes a otros complejos tempranos del Formativo en el área andina pero como unidad difiere de ellos; tal vez lo que hemos podido apreciar en el material, actualmente estudiado por Mejía Xesspe: lo publicado por Rebeca Carrión (1948), se refiere más bien, a época tardía.

Las fases Negritos y Paita (Lanning 1963), muestra algunas relaciones con Pacopampa, en las formas, jarras de cuello corto, borde evertido o expandido (Fig. 1, b, c), jarras de cuello alto, borde evertido, reforzado exteriormente $(21, b)$ o cuello estrecho $(21, a)$, bols de borde expandido, aunque estos son raros en Piura y muy frecuentes, en variedad de formas en Pacopampa; también es común, los labios dentados, hileras de puntuaciones en la base del cuello, tiras superpuestas, incisiones profundas, cortantes de cama sin pulir sobre superficie externa tosca, diseños geométricos, líneas simple (Fig. 21, o, p, u, x, z) o cruzadas $(21, \mathrm{i})$; sin embargo en Pacopampa, se observa mayor número de combinaciones y diseños figurativos; además de otras técnicas y pinteado pre-cocción.

Las jarras sin cuello y el empleo de engobe rojo, características de la fase Paita C, están presentes en Pacopampa desde temprano, al igual que la pintura roja post-cocción, en zo- nas o dentro de líneas incisas, que son rasgo de Paita, variante 1 .

En el valle de Virú, Guañape comparte algunas similitudes con Pacopampa, en el listón impreso con los dedos (Fig. 45) y listón inciso (Fig. 46), los tipos más tempranos de Guañape; también es común la aplicación de protuberancias circulares con puntuaciones centrales (Fig. 47 d, f) y figuras modeladas (Fig 47 e, f), principalmente de animales. No obstante, en Pacopampa, las tiras sobrepuestas y modelados nunca han sido numerosos aparecen desde muy temprano pero con ligera frecuencia en la parte media de la fase; des mismo modo, el punteado en zonas, algo tardío en Guañape, aparece en Pacopampa, escasamente, asociado a incisiones cortantes; las jarras grandes, boca constreñida, base cónica, el tipo más popular en Guañape, no ha sido reconstruido en $\mathrm{Pa}$ copampa, aunque son similares, las jarras de cuello corto, cuerpo globular, base redonda (Fig. 35, 2) y los bols de lados curvos, base redondeada (Fig. 35, 3) o lados derechos, base aplanada o convexa (Fig. 35, 4).

La cerámica pintada pre-cocción en zonas, rojo, blanco, gris, delimitadas por incisiones se asemeja a cerámica pintada de Bagua en el valle de Utcubamba y aunque greográficamente alejada, con la alfarería de la cuenca del norte del lago Titicaca (Kidder 11, 1943) ${ }^{9}$

La fase siguiente Pacopampa-Chavín muestra mayor número de elementos culturales de relación; pero la diversidad que se observa en la cerámica señala hacia futuras sub-divisiones cuando reunamos mayores datos.

Aunque tiene muchos elementos comparables con otros sitios formativos, difiere como complejo; la decoración más popular a base de círculos estampados, en variedad de combinación, la pintura roja post-cocción en las incisiones, los bols, jarras de cuello largo, jarras de asa estribo, fuertemente engrosadas en el labio; comparte con Kotosh Chavín, Rocas de Chavín de Huántar, Cupisnique, Ancón,

9 SHADY, Ruth y ROSAS, Hermilio. Informe preliminar de las exploraciones arqueológicas en la cuenca del Marañón, presentado al XXXIX Congreso Internacional de Americanistas. 


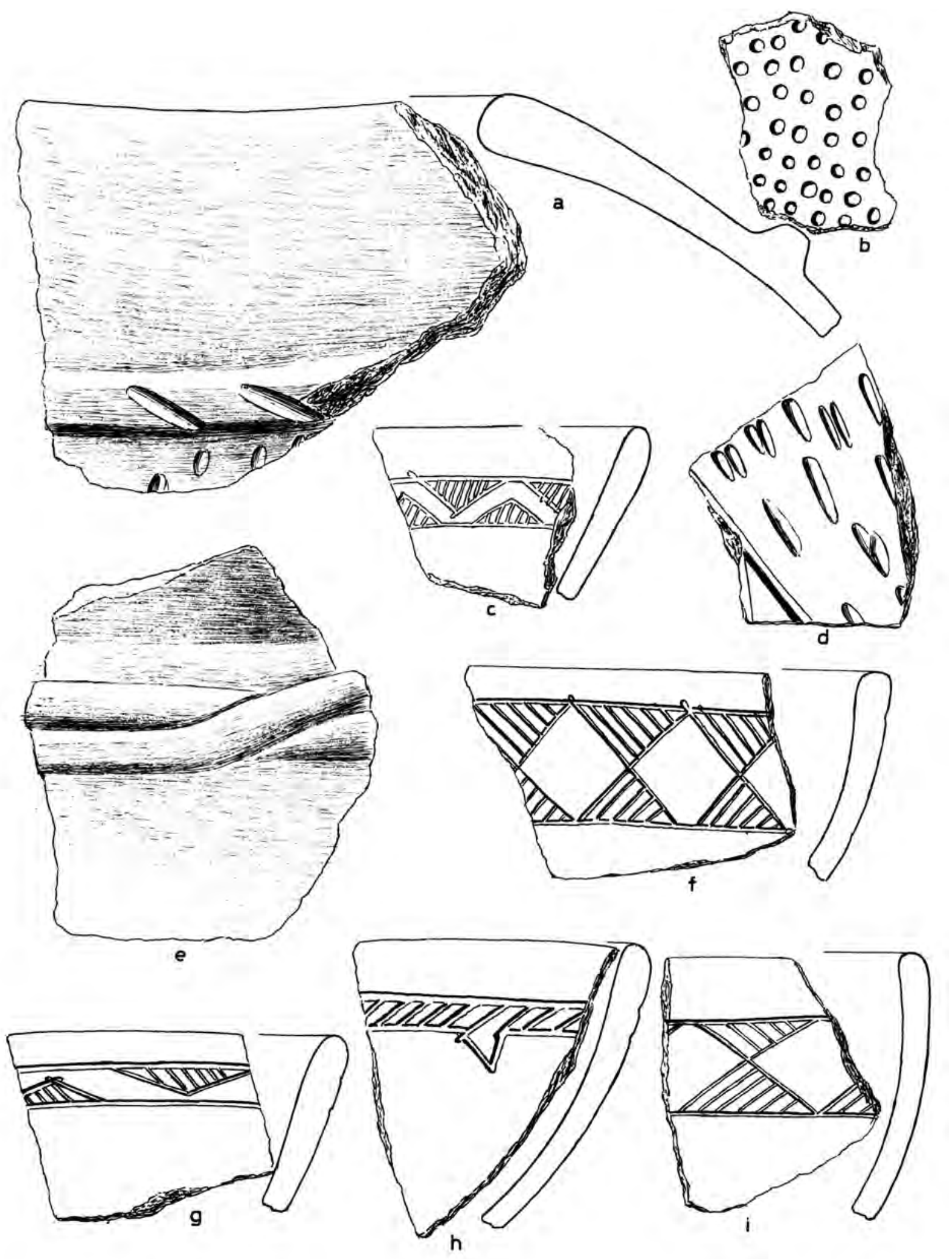

Figura 6. Pacopampa-Chavín. a-b, d-e: acordonado; c, f-i: rojo inciso fino. 


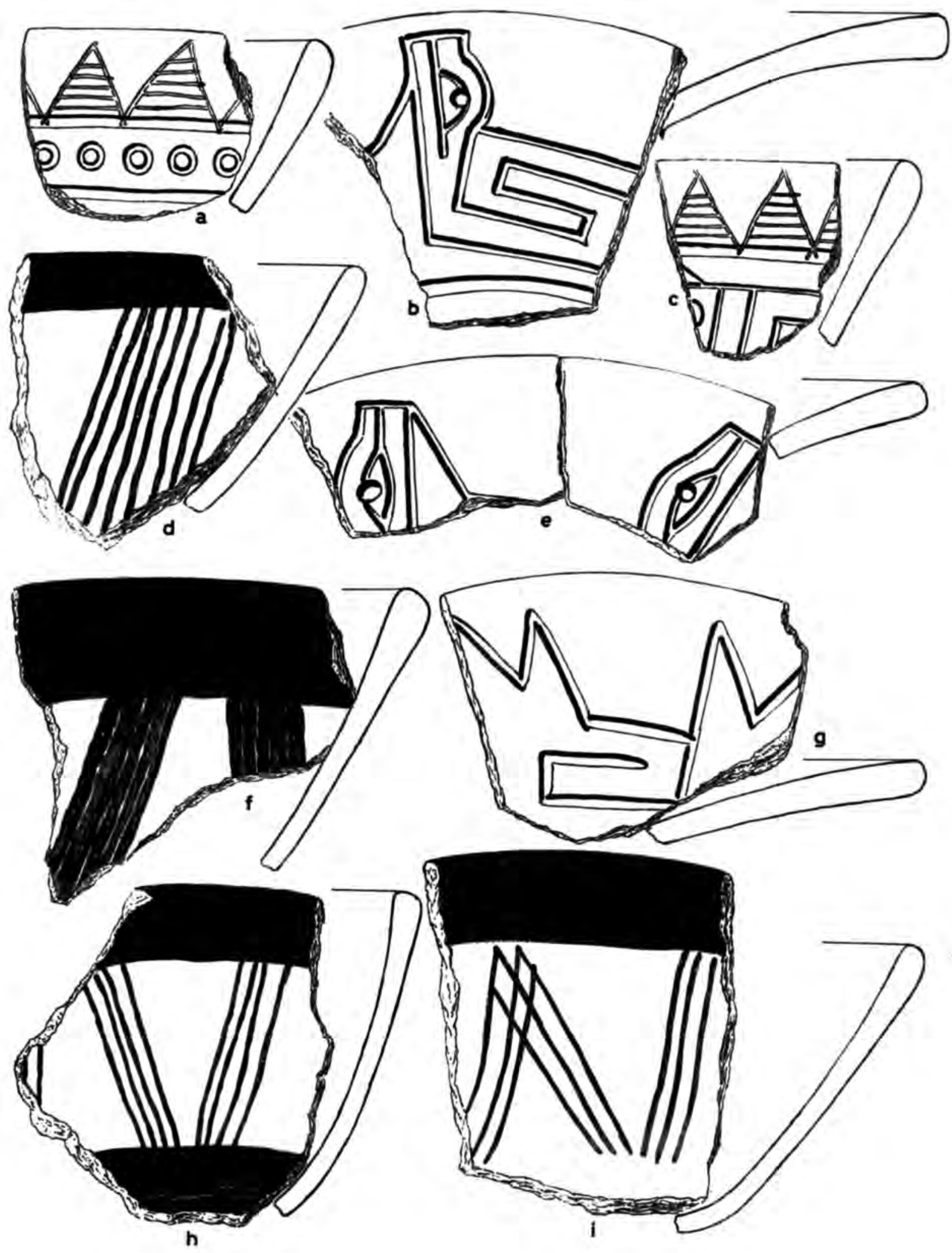

Figura 7. Pacopampa-Chavín. a,c: gris pulido; b, e, g: negro inciso; $d, f, h$, i: línea bruñida. 

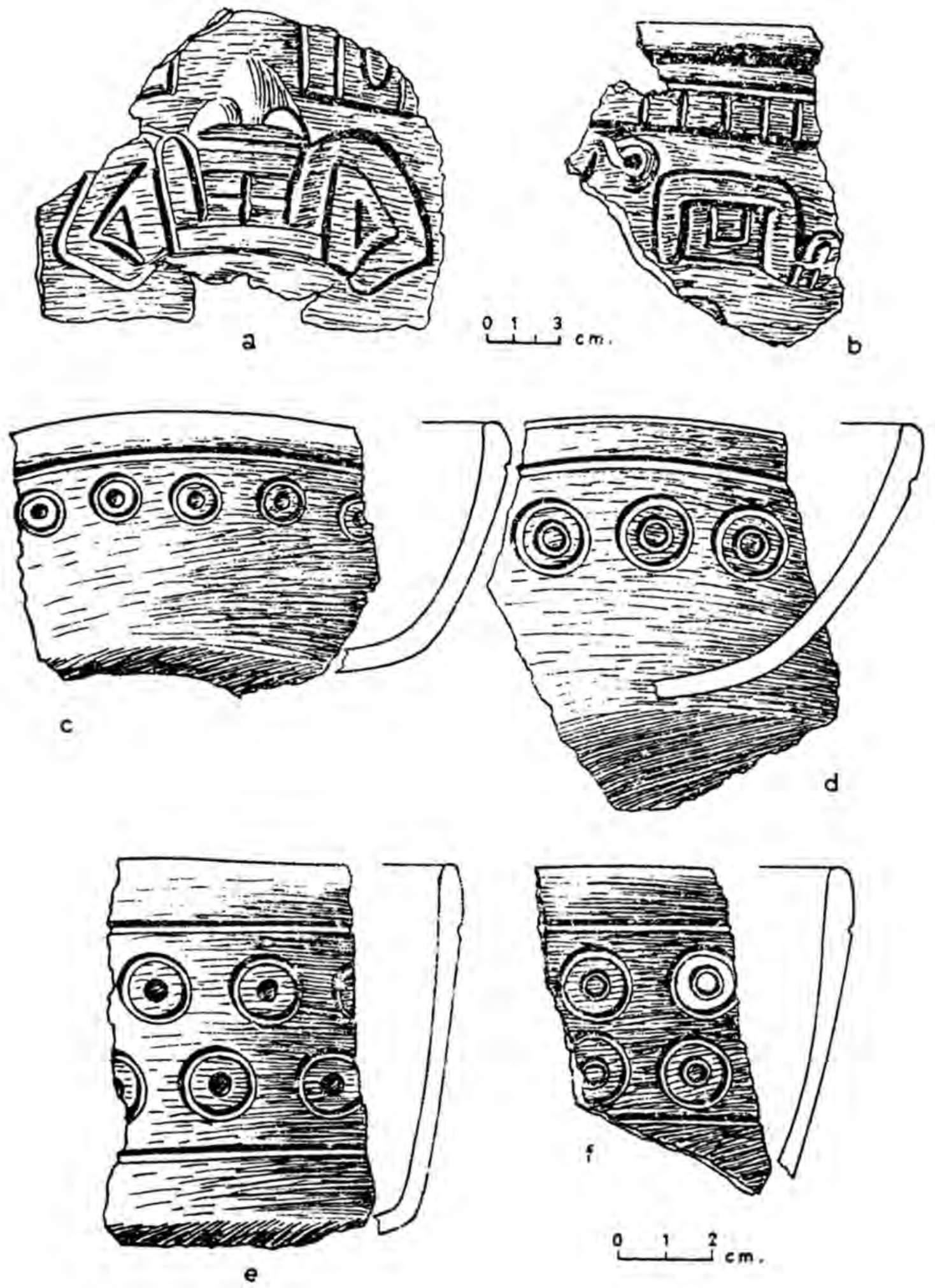

Figura 8. Pacopampa, Chavín. a, b: modelado cintado; c-f: gris pulido. 
fase $4^{10}$; sin embargo difiere de ellos, la pintura con grafito, las representaciones de serpientes o felinos y el mecido, no son frecuentes en Pacopampa, salvo los rasgos felínicos en el tipo Modelado Cintado, que está ausente en la mayoría de sitios; no se encuentra la profusión de técnica y motivos decorativos de la fase ofrendas de Chavín, Cupisnique o Ancón.

Con Kotosh, además de los elementos mencionados, comparte los bols con vertedera en el labio o lobulados y conjuntamente con Cupisnique los espejos azabache ${ }^{11}$, los entierros en posición flexionada con los huesos pintados de rojo; con Kuntur Wasi, el tipo Modelado cintado y los bols con labios almenados, lobulados, bocas felínicos de terminación romboidal y la base anular.

El tipo Rojo inciso con líneas sombreadas, ausente en los sitios Formativos mencionados, es típico de la costa Ecuatoriana, al igual que la decoración bruñida, en variedad de diseños, en la fase Machalilla.

La arquitectura muestra semejanza, por una parte, con Sechín, en la alternancia vertical-horizontal de las piedras; en la mampostería superior del Muro A y parte de Muro B, con la pared externa del Templo del Lanzón de Chavín de Huántar; así como también en el empleo de columnas, estelas, patios, escalinatas, galerías de desagüe, etc.

\section{Bibliografía}

BENNET, Wendell C. "Excavations in Bolivia", American Museum of Natural History, Anthropological Papers, vol. 35, pt. 4, pp. 329. 507, New York, 1936.

BENNET, Wendell C. "The Archeology of the Central Andes". En Handbook of South American Indians. Bureau of American Ethnology Bulletin, № 143, vol. 2, pp. 61-147, Washington D.C., 1946.

10 ROSAS, Hermilio. Ancón: Secuencia cultural del periodo Formativo, 1970.

11 En Ancón, también se encuentran los espejos de antracita.
CARRIÓN CACHOT, Rebeca. "La Cultura Chavín. Dos nuevas Colonias: Kuntur Wasi y Ancón". Revista del Museo Nacional de Antropología y Arqueología, vol. 2, № 1, pp. 99. 172, Lima, 1948.

IZUMI, Seiichi y Toshihiko SONO. "Andes 2: Excavations at Kotosh, Perú 1960", Peabody Museum, Harvard University, vol. 27, № 1, 1963.

LANNING, Edward. "A ceramic sequence for the Piura and Chira Coast, North Peru". University of California Publications in American Archeology and Ethnology, vol. 46, № 2, pp. 135-284, Berkeley, California, 1963.

LARCO HOYLE, Rafael. Los Cupisniques. Casa Editora La Crónica y Variedades, Lima 1941.

LARCO HOYLE, Rafael. "A Cultural Sequence for the North Coast of Peru". En Handbook of the South American Indians. Bureau of American Ethnology Bulletin, № 143, vol. 2, pp. 149-175, Washington.

LUMBRERAS, Luis y Hernán AMAT. "Informe preliminar sobre las galerías interiores de Chavín". Revista del Museo Nacional. T. XXXIV, pp. 143-195, Lima, 1969.

MEGGERS, Betty; Clifford EVANS; Emilio ESTRADA. "Early Formative Period of Coastal Ecuador: The Valdivia and Machalimma Phases". Smithsonian Contributions to Anthropology. Vol.1, Washington D.C. 1965.

REICHEN, Henry y Paule. "Recherches Arqueologiques dans les Andes de Cajamarca: Premier Rapport de la Mission Ethnologique Française au Perou Septentrional". Journal Societé des Americanistes de Paris, vol. 38, pp. 137. 174, 1949.

ROSAS LA NOIRE, Hermilio. La Secuencia Cultural del Periodo Formativo en Ancón. Tesis de Grado en el Programa Académico de Psicología y Ciencias Sociales, Universidad Nacional Mayor de San Marcos, Lima, 1970.

ROWE, John. "An Introdution to yhe Archeology of Cuzco". Papers. Peabody Museum, Harvard University, vol. 27, № 2, 1944. 
STRONG, William y Clifford EVANS. "Cul- TELLO, Julio C. Chavín, Cultura Matriz de la tural Stratigraphy in the Viru Valley, Northern civilización andina. Universidad Nacional MayPeru: The Formativa and Florecent Epochs". or de San Marcos. Lima. 1960.

Columbia Estudies en Archeology and Ethnology, vol. 4, Columbia University Press, New York, 1952.

TOSI, Joseph. "Zonas de vida natural en el Perú". Instituto Interamericano de Ciencias Agrícolas de la OEA, Zona Andina, Boletín TELLO, Julio C. Arqueología del Valle de CasTécnico. № 5, 1960.

ma. Universidad Nacional Mayor de San Marcos, Lima, 1956. 